\title{
DEVELOPMENT OF THE PROCESS OF PASSIVATION OF ZINC SURFACES IN MOLYBDATE- CONTAINING SOLUTIONS
}

\author{
${ }^{1}$ Venera ALESHINA, ${ }^{1}$ Aleksey ABRASHOV, ${ }^{1}$ Nelya GRIGORYAN, ${ }^{1}$ Ekaterina TROFIMOVA \\ ${ }^{1}$ MUCTR - D. Mendeleev University of Chemical Technology of Russia, Moscow, Russia, \\ aleshinavh@gmail.com
}

https://doi.org/10.37904/metal.2021.4176

\begin{abstract}
The work is devoted to the study of the process of passivation of zinc and its alloys in ecologically safe molybdate-containing solutions in order to replace highly toxic solutions of black chromate passivation.

The concentration range of the solution components was determined, in which black coatings are deposited, corresponding to a point of 10 on a ten-point color scale. It was found that the optimal pH values of the solution are in the range from 4.8 to 5.2 units. At lower $\mathrm{pH}$ values, adhesion deteriorates and the black color of coatings degrades, at higher $\mathrm{pH}$ values, coatings do not form at all. High-quality deep black coatings (10 points) are formed at temperatures of $45-85^{\circ} \mathrm{C}$.

The color of the coatings changes from rainbow to black depending on the duration of their formation; the coatings of deep black color are formed with a process duration of at least 5 minutes. It was found that the coatings contain molybdenum oxides (IV, V, VI) and zinc oxides.

Has been developed the technological process of passivation of zinc surfaces in a solution containing $(\mathrm{g} / \mathrm{l})$ : 14-20 $\left(\mathrm{NH}_{4}\right)_{6} \mathrm{Mo}_{7} \mathrm{O}_{24}$; $10-18 \mathrm{CH}_{3} \mathrm{COONa} ; 1-5 \mathrm{NiSO}_{4} \cdot 6 \mathrm{H}_{2} \mathrm{O}$, which allows the formation of black molybdenumcontaining coatings at $\mathrm{t}=45-85^{\circ} \mathrm{C}$ and $\tau=7-10 \mathrm{~min}$, comparable in protective and optical characteristics with black chromate coatings.
\end{abstract}

Keywords: Corrosion protection, molybdenum-containing coatings, chromate-free passivation of zink plated steel, black decorative coatings, black light absorbing coatings

\section{INTRODUCTION}

Black passivating conversion coatings on zinc surfaces are used in a number of industries as protective and decorative coatings (furniture fittings, hardware, panels, instrument accessories and etc.), as well as lightabsorbing coatings in solar technology (in collectors that convert light energy into thermal energy, and in other optical devices). To obtain such coatings, converting solutions based on hexavalent chromium compounds are used, in which chromate films are formed, which have a high protective ability and the ability to «self-heal» in case of mechanical damage to the film. The coatings consist mainly of chromium hydroxochromates $\mathrm{Cr}(\mathrm{OH}) \mathrm{CrO}_{4}$ (up to $95 \%$ ) and zinc $\mathrm{Zn}(\mathrm{OH})_{2} \mathrm{CrO}_{4}$ (up to $5 \%$ ), as well as a small amount of copper or silver oxides, which give the coatings a black color [1]. The disadvantages of chromating solutions are their high aggressiveness and toxicity. The use of solutions and coatings containing $\mathrm{Cr}^{6+}$ compounds has been limited since 2000 by regulatory documents in a number of countries in Europe, Asia and America, as well as in the Russian Federation [2-5].

An environmentally safe substitute for chromate passivation of zinc and its alloys can be passivation in molybdate-containing solutions, since molybdate ions, as is known, just like chromate ions, inhibit the corrosion processes of these metals [6-9]. 
Taking into account the above, this study is devoted to the development of a low-toxic process of black passivation of the surface of zinc and its alloys, which is not inferior to existing analogues in terms of protective and optical characteristics, in solutions based on molybdenum compounds.

\section{EXPERIMENTAL MATERIALS}

As samples, we used galvanized plates of cold rolled steel grade 1008 measuring $0.2 \mathrm{~cm} \times 0.2 \mathrm{~cm}$ and plates made of alloy Zamak ZL5. Zinc plating of steel samples was carried out in a weakly acidic electrolyte of composition (g/l): 60-120 ZnCl $2 ; 200-220 \mathrm{NH}_{4} \mathrm{Cl}_{2} ; 0-20 \mathrm{H}_{3} \mathrm{BO}_{3} ; \mathrm{i}=0,2-0,3 \mathrm{~A} / \mathrm{dm}^{2} ; \mathrm{t}=18-30{ }^{\circ} \mathrm{C} ; \mathrm{pH}=4.5-6.0$. The steel samples were preliminarily degreased in an alkaline solution containing $100 \mathrm{ml} / \mathrm{l}$ TsKN-63 for 5-10 minutes at a temperature of $30-70{ }^{\circ} \mathrm{C}$ in an ultrasonic bath «Ultrasonic washing unit», after which they were etched in a solution of $10 \%$ hydrochloric acid and activated in $10 \%$ sulfuric acid. Before passivation of zinc surfaces, they were clarified in a $0.5 \%$ solution of nitric acid, followed by rinsing in distilled water.

The XPS spectra of conversion coatings were recorded using a special CLAM100 camera installed on an HB100 Auger microscope (Vacuum Generators, GB). According to the results of the study, the survey spectra of the coatings were obtained, which were decomposed into the component spectra of the elements after subtracting the linear background [10].

The reflectance of solar radiation of the coated samples was determined with an FM-59M photometer. The value of the absorption coefficient of solar radiation $\alpha_{s}$ was calculated by the formula: $\alpha_{s}=1-\rho_{s}$, where $\rho_{s}$ is the reflection coefficient of solar radiation.

The limiting wetting angle of the investigated surfaces was determined using the «Goniometer LK-1» installation. Photographs of drops were taken with the Levenhuk C310 NG camera, and then the limiting wetting angle was calculated using the DropShape software.

Corrosion tests of samples with the obtained coatings were carried out in a salt fog chamber Ascott S450iP (Great Britain) in accordance with the international standard ASTM B117.

As an object of comparison, a black chromate coating was chosen, obtained using the German composition Corroblack, which is used by a number of domestic manufacturers.

\section{EXPERIMENTAL}

It is known that solutions for obtaining black molybdenum-containing coatings must contain ammonium paramolybdate $\left(\left(\mathrm{NH}_{4}\right)_{6} \mathrm{Mo}_{7} \mathrm{O}_{24}\right)$ and sodium acetate $\left(\mathrm{CH}_{3} \mathrm{COONa}\right)[11]$.

\subsection{Determination of the molybdenum-containing coatings depositing process parameters}

The experiments made it possible to determine the range of concentrations of ammonium paramolybdate and sodium acetate, in which it is possible to obtain black coatings corresponding to a point of 10 on a ten-point color scale (Figure 1). It should be noted, however, that the forming coatings, including in the selected area of component concentrations, were characterized by insufficiently high adhesion, as a result of which the coatings were smeared - leaving marks on the hands. In order to eliminate this drawback, a small amount of nickel ions was introduced into the solution, which, as is known, have a beneficial effect on the adhesion of conversion coatings (phosphating and etc.) $[12,13]$. It turned out that in the presence of nickel ions (in the form of $\mathrm{NiSO}_{4} \cdot 6 \mathrm{H}_{2} \mathrm{O}$ ) in the solution of $0.22-1.12 \mathrm{~g} / \mathrm{l}$, the coatings formed in them cease to smear, and their deep black color is not disturbed.

It was also found that the optimal $\mathrm{pH}$ values of the solution are in the range of 4.8-5.2 units. At lower $\mathrm{pH}$ values, adhesion deteriorates, and the black color of the coatings degrades, at higher $\mathrm{pH}$ values, the coatings do not form at all. The study of the effect of the temperature of the solution on the characteristics of the coatings showed that high-quality coatings of deep black color (10 points) are formed at temperatures of $45-85^{\circ} \mathrm{C}$. In 
colder solutions, coatings with poor adhesion are formed, and in hotter solutions, coatings of a rainbow color are formed.

\begin{tabular}{|c|c|c|c|c|c|c|c|}
\hline & \multicolumn{6}{|c|}{ Concentration $\left(\mathrm{NH}_{4}\right)_{6} \mathrm{Mo}_{7} \mathrm{O}_{24}(\mathrm{~g} / \mathrm{l})$} \\
\hline & & 10 & 12 & 14 & 16 & 18 & 20 \\
\hline \multirow{6}{*}{ 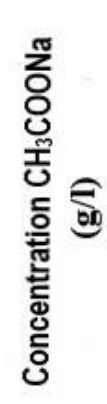 } & 10 & 8 & 8 & 10 & 10 & 10 & 10 \\
\hline & 12 & 8 & 8 & 10 & 10 & 10 & 10 \\
\hline & 14 & 8 & 8 & 8 & 10 & 10 & 10 \\
\hline & 16 & 8 & 8 & 8 & 10 & 10 & 10 \\
\hline & 18 & 8 & 8 & 8 & 8 & 10 & 10 \\
\hline & 20 & 8 & 8 & 8 & 8 & 8 & 8 \\
\hline
\end{tabular}

\begin{tabular}{|l|l|l|l|l|l|l|l|l|l|}
\hline & & & & & & & & & \\
\hline 1 & 2 & 3 & 4 & 5 & 6 & 7 & 8 & 9 & 10 \\
\hline \multicolumn{10}{|c|}{ Color characteristic(points) } \\
\hline
\end{tabular}

Figure 1 Dependence of the appearance of coatings on concentration $\left(\mathrm{NH}_{4}\right)_{6} \mathrm{Mo}_{7} \mathrm{O}_{24}$ and $\mathrm{CH}_{3} \mathrm{COONa}$

In the course of experiments, it was found that the color of the coatings changes from rainbow to black, depending on the duration of their formation. Deep black coatings are formed with a process duration of at least 5 minutes. To explain this phenomenon by the method of X-ray photoelectron spectroscopy, it was investigated how the composition of the coatings changes as they are formed. Survey XPS spectra revealed the presence of zinc, oxygen, and molybdenum compounds of various valences (IV, V, VI) in the coating. Individual spectra of molybdenum in coatings formed in $0.5,3$ and 10 min showed that with an increase in the duration of the process, the content of molybdenum (V) oxide increases, molybdenum (VI) oxide decreases, and the content of molybdenum (IV) oxide remains practically unchanged. The consequence of this, apparently, is the dependence of the color of the coating on the duration of treatment.

Taking into account the results of XPS spectroscopy, the following mechanism of coating formation can be assumed. Electrons released during the anodic dissolution of the zinc substrate (1) go to the reduction of $\mathrm{Mo}^{6+}$ to $\mathrm{Mo}^{5+}$ and $\mathrm{Mo}^{4+}(2-3)$ :

$\mathrm{Zn} \rightarrow \mathrm{Zn}^{2+}+2 \mathrm{e}$

$2\left(\mathrm{Mo}_{7} \mathrm{O}_{24}\right)^{6-}+14 \mathrm{e}^{-}+13 \mathrm{H}^{+} \rightarrow 7 \mathrm{Mo}_{2} \mathrm{O}_{5}+13 \mathrm{OH}^{-}$

$\left(\mathrm{Mo}_{7} \mathrm{O}_{24}\right)^{6-}+14 \mathrm{e}^{-}+10 \mathrm{H}^{+} \rightarrow 7 \mathrm{MoO}_{2}+10 \mathrm{OH}^{-}$

$\left(\mathrm{Mo}_{7} \mathrm{O}_{24}\right)^{6-}+14 \mathrm{e}^{-}+3 \mathrm{H}^{+} \rightarrow 7 \mathrm{MoO}_{3}+3 \mathrm{OH}^{-}$

Due to the occurrence of reactions (2-4), alkalization of the solution occurs at the metal-solution interface, leading to the deposition of a conversion film consisting mainly of molybdenum oxides of various valences and zinc oxide.

\subsection{Tests of the coatings}

The optical characteristics of molybdenum-containing coatings are studied depending on the duration of the passivation process. It was found that as molybdenum-containing coatings are formed, the absorption 
coefficient of solar radiation increases and by the end of the process reaches a value of $\alpha_{s} \approx 0.85$, which is comparable to the analogous characteristic of chromate black coatings $\alpha_{s} \approx 0.93$ (Figure 2). Tests of coatings for resistance to aging showed that after 60 days black molybdenum-containing coatings not only did not lose their black color, but their absorption coefficient even increased slightly (from 0.85 to 0.89 ). This indicator for black chromate coating after 60 days decreased from 0.93 to 0.91 .

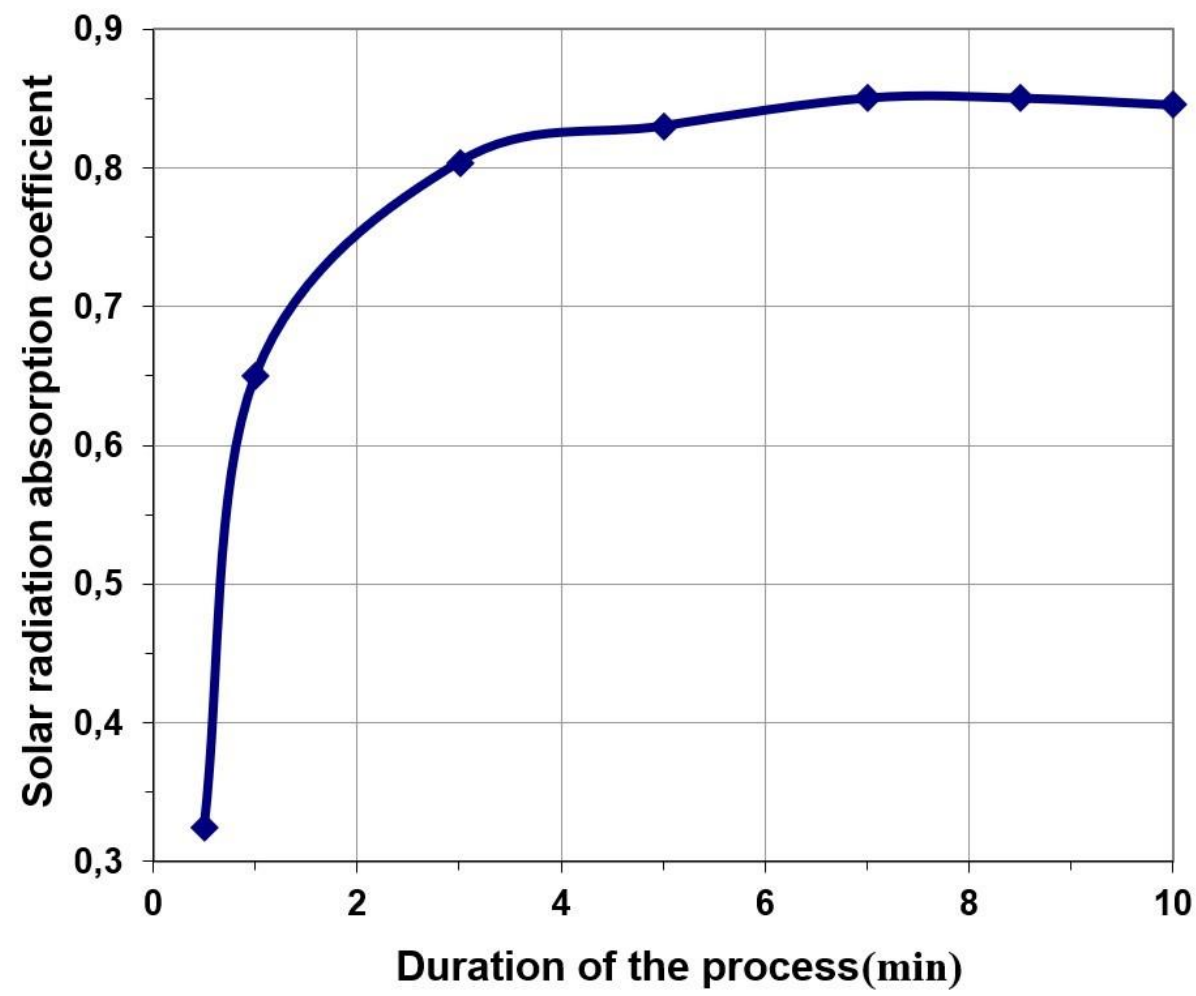

Figure 2 Dependence of the optical characteristics of molybdenum-containing coatings on the duration of the process

It is known that the limiting wetting angle of surface indicates the degree of surface hydrophobicity and can serve as a criterion for its corrosion characteristics [14]. Studies have shown that molybdenum-containing coatings formed within 7-10 minutes are characterized by the largest limiting wetting angle $\left(70^{\circ}\right)$ and, therefore, the greatest corrosion resistance. For comparison, it should be noted that the limiting wetting angle of the black chromate coating is only 47 degrees (Table 1 ).

Table 1 Dependence of the limiting wetting angle of coatings on the duration of the process

\begin{tabular}{|c|c|c|c|c|c|c|c|}
\hline Process duration (min) & 0.25 & 0.5 & 1 & 3 & 5 & 7 & 10 \\
\hline Limiting wetting angle ( $\left.{ }^{0}\right)$ & 55 & 57 & 60 & 64 & 66 & 70 & 70 \\
\hline
\end{tabular}

Corrosion tests in a salt fog chamber showed that the time until the first spots of corrosion of zinc with black molybdenum-containing coatings appears is 65 hours, and with black chromate coatings it is slightly longer 72 hours.

The possibility of forming black molybdenum-containing coatings on the alloy Zamak ZL5 has been investigated. It should be noted that during passivation in the developed solution of zinc alloy Zamak ZL5, the characteristics of the forming coatings do not differ from coatings on a zinc substrate, while black chromating solutions do not allow obtaining black coatings on Zamak. 


\section{CONCLUSION}

A technological process has been developed for passivation of zinc surfaces in a solution containing (g/l): 14-20 $\left(\mathrm{NH}_{4}\right)_{6} \mathrm{Mo}_{7} \mathrm{O}_{24} ; 10-18 \mathrm{CH}_{3} \mathrm{COONa} ; 1-5 \mathrm{NiSO}_{4} \cdot 6 \mathrm{H}_{2} \mathrm{O}$, which makes it possible to form at $\mathrm{t}=45-85$ ${ }^{\circ} \mathrm{C}$ and $\tau=7-10$ min black molybdenum-containing coatings comparable in protective and optical characteristics with black chromate coatings.

\section{ACKNOWLEDGEMENTS}

\section{The work was supported by the Mendeleev University of Chemical Technology of Russia. Project Number X-2020-027.}

\section{REFERENCES}

[1] DINGWERTH, B. The Second Conversion Coating - Final Finishing Black Passivates with Trivalent Chromium Based Post-dip Solutions. Electroplating and surface treatment. 2009, vol. 17, no 1, pp. 38-48.

[2] Directive 2011/65/EC (RoHS II) of the European Parliament and of the Council of 8 June 2011 «On the restriction of the use of certain hazardous substances in electrical and electronic equipment».

[3] Directive 2002/96/EC of the European Parliament and of the Council of 27 January 2003 «Waste electrical and electronic equipment».

[4] Directive 2000/53/EC of the Parliament and of the Council of Europe of 18 September 2000 «End-of-livevehicles», Official Journal of the European Communities L269.

[5] Regulation (EC) No 1907/2006 of the European Parliament and 2357 of the EU Council of 18 December 2006 concerning the rules for registration, assessment, authorization and restriction of chemicals (REACH), an institution of the European Chemicals.

[6] WHARTON, J.A., ROSS, D.H., TREACY, G.M., et al. An EXAFS investigation of molybdate-based conversion coatings. J. Appl. Electrochem. 2003, vol. 33, no 7, pp. 553-561.

[7] KONNO, H., NARUMI, K., HABAZAKI, H. Molybdate/AI (III) composite films on steel and zinc-plated steel by chemical conversion. Corros. Sci. 2002, vol. 44, no 8, pp. 1889-1900.

[8] MAGALHAES, A.A.O., MARGARIT, I.C.P., MATTOS, O.R. Molybdate conversion coatings on zinc surfaces. J. Electroanal. Chem. 2004, vol. 572, no 2, pp. 433-440.

[9] SONG, Y.K., MANSFELD, F. Development of a molybdate-phosphate-silane-silicate (MPSS) coating process for electrogalvanized steel. Corros. Sci. 2006, vol. 48, pp. 54-164.

[10] WAGNER, C.D., RIGGS, W.M., DAVIS, L.E., MOULDER, J.F., et al. Handbook of X-Ray Photoelectron Spectroscopy. Physical Electronics Devision. Minnesota: Perkin Elmer Corporation, Eden Prairie, 1979.

[11] MESHALKIN, V.P., ABRASHOV, A.A., VAGRAMYAN, T.A., GRIGORYAN, N.S., et al. Development of Composition and Investigation of Properties of a New, Environmentally Friendly Molybdenum-Containing Decorative Protective Conversion Coating on Zinc-Plated Surfaces. Doklady Chemistry. 2018, vol. 480, no. 5, pp. 555-558.

[12] ABRASHOV, A.A, GRIGORYAN, N.S, VAGRAMYAN, T.A., ASNIS N.A. On the Mechanism of Formation of Conversion Titanium-Containing Coatings. Coatings. 2020, vol. 10, no 328, pp. 1-11.

[13] MAZUROVA, D.V., GRIGORYAN, N.S., AKIMOVA, E.F., ABRASHOV, A.A., et al. Simultaneous phosphating of steel, galvanized steel and aluminum. Corrosion: materials, protection. 2009, vol. 3, pp. 27-34.

[14] ABRASHOV, A.A., GRIGORYAN, N.S., VOLKOVA, A.E., YAROVAYA, O.V., et al. Protective titanium-containing nanocoatings on galvanized steel. Electroplating and surface treatment. 2016, vol. 24, no. 2, pp.28-34. 